\title{
UM ESTUDO SOBRE SISTEMAS ERP GRATUITOS PARA EMPRESAS
}

\author{
A STUDY ABOUT FREE ERP SYSTEMS FOR COMPANIES
}

Augusto Frigeri Capone - augustofcapone@gmail.com Faculdade de Tecnologia de Catanduva - Catanduva - São Paulo - Brasil

Giovani Ferro - giovani.ferro@fatec.sp.gov.br Faculdade de Tecnologia de Catanduva - Catanduva - São Paulo - Brasil

Liriane Soares de Araújo - lirianearaujo@hotmail.com Faculdade de Tecnologia de Catanduva - Catanduva - São Paulo - Brasil

DOI: 10.31510/infa.v18i1.1104

Data de submissão: 13/04/2021

Data do aceite: $09 / 07 / 2021$

Data da publicação: 30/07/2021

\begin{abstract}
RESUMO
Para que uma empresa tenha vantagens competitivas no mercado de trabalho, ela precisa estar atenta aos avanços tecnológicos, e considerando o crescente avanço da tecnologia no decorrer dos anos, pode-se afirmar que, as mesmas precisam se adequarem na utilização de ferramentas para apoio à tomada de decisões. Uma das ferramentas utilizadas neste contexto é Enterprise Resource Planning (ERP), que visa automatizar funcionalidades de negócio, possuindo um banco de dados integrado e único a fim de agilizar e facilitar a comunicação e transparência dos dados. Sendo assim, o objetivo deste trabalho é mostrar algumas vantagens que uma ferramenta gratuita de ERP pode oferecer, bem como alguns impactos desta ferramenta no âmbito organizacional. A metodologia de pesquisa abordada envolve análise bibliográfica descritiva de natureza aplicada com abordagem qualitativa, juntamente com um estudo sobre algumas ferramentas gratuitas por meio de análise comparativa. Espera-se auxiliar empresas na escolha, implantação e uso de ferramentas tecnológicas para potencializar os processos de negócios.
\end{abstract}

Palavras-chave: Enterprise Resource Planning. Ferramenta Gratuita. Automação.

\begin{abstract}
In order for a company to have competitive advantages in the job market, it needs to be attentive to technological advances, and considering the growing advancement of technology over the years, it can be said that they need to adapt to the use of tools for support taken of decisions. One of the tools used in this context is Enterprise Resource Planning (ERP), which aims to automate business functionalities, having an integrated and unique database in order to streamline and facilitate data communication and transparency. Therefore, the objective of this work is to show some advantages that a free ERP tool can offer, as well as some impacts of this
\end{abstract}


tool in the organizational scope. The research methodology covered involves the descriptive bibliographic analysis of an applied nature with a qualitative approach, together with a study on some free tools through comparative analysis. It is expected to assist companies in choosing, implementing and using technological tools to enhance business processes.

Keywords: Enterprise Resource Planning. Free Tool. Automation.

\section{INTRODUÇÃO}

Um dos problemas que foram decorrentes no século XX em relação às empresas, foi a má administração de seus recursos e tal fato se deve pelo alto custo de ferramentas tecnológicas. Segundo Sebrae (2013), em pesquisa realizado naquele ano, pôde-se identificar que, se comparado aos anos de 2006 e 2007, a taxa de mortalidade das empresas vem caindo constantemente no decorrer dos anos por considerar o aumento do uso e a boa utilização das tecnologias e ferramentas de gestão disponíveis.

Muitas organizações de pequeno porte optam por não implantar um sistema de informação nos primeiros meses de negócio, já que o processo de escolha e obtenção de uma ferramenta tecnológica se torna algo difícil devido ao pouco conhecimento e investimento das mesmas. Sendo assim, este artigo objetiva apresentar softwares gratuitos de sistemas ERP Enterprise Resource Planning, mostrando algumas funcionalidades e uma breve análise comparativa.

De meados dos anos 90 a 2000, as empresas passaram a adotar medidas tecnológicas para seu setor administrativo e foi neste tempo que surgiu a ferramenta ERP, que trouxeram benefícios, tornando-se uma ferramenta base de qualquer negócio por possuir uma grande quantidade de módulos, os quais abrangem funcionalidade de vários departamentos integrados como finanças, marketing, venda, contabilidade, RH. Segundo Mendes e Escrivão Filho (2003, p. 278), "a integração é possível pelo compartilhamento de informações comuns entre os diversos módulos, armazenadas em um único banco de dados centralizado”. Embora essa ferramenta seja muito popular nos dias de hoje, para muitas empresas, principalmente as empresas de pequeno porte, ainda é difícil adquirir um sistema pago, já que muitas destas ferramentas geram mensalidades durante longos meses. Como forma de solução, tais empresas podem recorrer a utilização de programas gratuitos como é mostrado nesta pesquisa. 


\section{FUNDAMENTAÇÃO TEÓRICA}

\subsection{Sistemas de Informação}

Nos anos 90, com o crescente avanço das indústrias e com o surgimento constante de novas empresas, o mercado se tornava cada vez mais competitivo e cada vez mais as empresas buscavam um diferencial para se destacar diante de milhares de outras concorrentes. Foi nesta época, em que as empresas passaram a dar maior importância para os gerenciamentos de dados dentro de suas organizações, surgindo assim novas tecnologias no mercado. Segundo Mattos (2005, p. 5-6), um sistema de informação é “um conjunto de módulos (objetos) de comunicação, de controle, de memória e de processadores interligados entre si através de uma rede com protocolo comum". Assim, é possível concluir que um sistema de informação pode ser definido como um sistema responsável por fazer o processamento de uma informação e responsável por fazer a comunicação de dados entre uma máquina e outra. Enquanto para Albertão (2005, p. 67), sistema de informação é definido como "uma série de elementos ou componentes interrelacionados, numa ordem específica, que coletam (entrada), manipulam (processamento), disseminam (saída) os dados e informações”. O ERP surge então como uma boa ferramenta para se manter um sistema de informação integro e de rápido acesso às informações dentro de uma empresa, sendo umas das ferramentas mais utilizadas atualmente no mercado por empresas de todos os ramos e setores.

\subsection{Sistemas de Informação Integrado (ERP)}

A primeira vez que se foi ouvido o termo ERP foi em meados dos anos 90, com o surgimento de novos sistemas de informação integrados para o mercado, que agrupam diferentes partes de uma empresa como os setores de finanças, estoque, administrativo, vendas, entre outros. Zwicker e Souza (2011, p. 64) definem que "os sistemas ERP são sistemas de informação integrados adquiridos na forma de pacotes comerciais de softwares com a finalidade de dar suporte a maioria das operações de uma empresa”. Segundo Ferreira e Silva (2004, p. 10), um ERP fornece "funcionalidades que suportam as atividades dos diversos processos das empresas", sendo capazes de agrupar todas as atividades da mesma, fazendo a junção dos sistemas em uma única plataforma e banco de dados, por isso o nome denominado "integrado", 
pois o ERP integra as partes (setores) de uma empresa.

Algumas vantagens que os sistemas ERP podem trazer, segundo Mendes e Escrivão Filho (2003, p.7) são: “Aumento de valor percebido pelos investidores e pelo mercado; Agilidade nas oportunidades de negócios; Visibilidade; Base única; Informação em tempo real; Atendimento a requerimentos globais, regionais e locais em um único sistema; e Suporte à estratégia de e-business". Segundo Oliveira (1992, p. 54), com o uso correto de um sistema ERP, é possível se obter as seguintes vantagens como: Redução dos custos das operações, Melhoria no acesso às informações, na produtividade, nos serviços, na tomada de decisão, na estrutura organizacional e de poder, na adaptação da empresa para enfrentar acontecimentos não previstos e Redução do grau de centralização de decisões na empresa. É relevante enfatizar que "o fato de o executivo poder contar com informações adequadas e oportunas é de relevância capital para a tomada de decisão eficaz” (REZENDE; ABREU, 2013, p. 88).

\subsection{Mercado de Softwares}

Nesta seção são apresentados três tipos de mercados de softwares para melhor compreensão de formas de aquisição dos ERPs. São eles:

- Mercado de Softwares Proprietários: Uma das formas comuns de se adquirir um sistema de informação é através da compra deles ou aluguel, pagando uma mensalidade ou anuidade. Muitos destes programas podem ser adquiridos de forma online em plataformas Web. Segundo Aquino (2015 p.17), estes softwares proprietários: “são desenvolvidos por pessoas ou empresas que vendem aos usuários uma licença restrita de uso. O usuário é proibido de compartilhar o software com outras pessoas." Em alguns casos, é definido o número de cópias que podem ser instaladas. Hexsel (2002, p.22) reforça a ideia, relatando que "software proprietário (não-livre) geralmente á produzido com a finalidade de obtenção de lucro" e, portanto, está sujeito à três tipos principais de pressões de mercado: “[1] inclusão de funcionalidades 'imprescindíveis' (e frequentemente inúteis), [2] obsolescência programada para possibilitar a venda de novas versões, e [3] prazos de desenvolvimento e testes muito curtos para atender às pressões já mencionadas" (HEXSEL, 2002, p.22). Segundo Aquino (2015), é possível entender que alguns softwares proprietários impõem algumas restrições aos usuários e isto gera uma desvantagem para empresas de pequeno porte, já que para cada usuário, a empresa deve investir um valor para obtenção de uma nova 
licença, e pode não ser possível o investimento devido aos baixos recursos.

- Mercado de Softwares Desenvolvidos: Outra categoria de mercado é através das criadoras de sistemas conhecidas como Software House, ou com sua tradução para a língua portuguesa "Empresa de Software". Exige um custo mais alto se comparado aos outros mercados comerciais devida a alta atenção que esse modelo tem em atender seus clientes. Segundo Mendes e Escrivão Filho (2003, p. 288), este tipo de mercado "consiste num projeto longo e caro, sendo necessária cautela na previsão do tempo de implantação e dos custos envolvidos". Segundo os autores (2003), os motivos para tais softwares terem um preço mais elevado, deve-se ao: Valores de custo do sistema que é diferente de um fabricante para outro; Quantidade de módulos a serem implantados; Quantidade de Licenças a serem adquiridas de horas trabalhadas pelas empresas de consultoria e ou fornecedora do sistema; Modificações a serem realizadas no sistema de acordo com as necessidades da empresa; Investimento em hardware necessário para o sistema; e Política de treinamento adotada pela empresa. De acordo com Mendes e Escrivão Filho (2003), há uma variação de custos entre fabricante devido que, cada projeto pode ser avaliado financeiramente diferente um do outro, já que em cada caso pode ser exigido necessidades diferentes em seus projetos. No caso de módulos a serem acrescentados, seria o exemplo desta variação de preço, já que a criação de cada módulo geraria mais horas trabalhadas pelos funcionários. O número de licenças, ou de usuários que podem acessar o programa também é algo a ser considerado na hora de precificar estes sistemas. Embora seja também custoso ao usuário, acaba sendo um diferencial se comparado com os demais mercados, sendo a obtenção de um novo módulo ou alguma alteração, personalizando o software de acordo com as regras de negócios. Sendo assim, estes tipos de softwares são desenvolvidos exclusivamente para as empresas que solicitarem o serviço, criando um sistema único que deve atender todas as necessidades que daquela determinada empresa.

- Mercado de Softwares Gratuitos: A obtenção de um sistema pode ser através de um mercado de softwares proprietários ou desenvolvidos, porém, por de trás destes mercados existem uma cobrança, seja ela por desenvolver o sistema, como no caso de softwares desenvolvidos, ou pagar uma taxa para poder usar o sistema, como no caso de softwares proprietários. Sendo assim, vale comentar que este artigo foca em sistemas que sejam gratuitos, e que tragam impactos positivos, principalmente para empresas de pequeno porte, facilitando a aquisição da ferramenta. Segundo Hexsel (2002, p.20), “a característica mais 
importante do software livre é a liberdade de uso, cópia, modificações e redistribuição”. O autor (2002) ainda complementa que livre deve ser a liberdade para usar, copiar, modificar e redistribuir software. É possível se entender que, software livre (Free Software) é um programa no qual o usuário tem a liberdade de usá-lo ou até mesmo modificá-lo, já que muitas vezes tem o seu código fonte disponibilizado. Contudo, o termo livre e o termo gratuito se distinguem um do outro. Segundo Hexsel (2002, p. 4) "existem programas que podem ser obtidos gratuitamente, mas que não podem ser modificados, nem redistribuídos”. Embora haja essa distinção de livre para gratuito, em ambos, o usuário pode desfrutar do sistema de maneira que não será gerado nenhum custo a ele. Algumas das vantagens de se utilizar um software livre, segundo Hexsel (2002), são: Valores de custo social baixo; Independência de tecnologia proprietária e de fornecedor único; Desembolso inicial baixo; Não obsolescência do hardware; Robustez e segurança; Possibilidade de adequar aplicativos e redistribuir versão alterada; Apoio ao suporte de forma gratuita; e Sistemas e aplicativos configuráveis.

Quando fala-se em softwares gratuitos, é possível se deparar com vários termos, existindo diferenças entre eles, conforme relata Garcia (2005):

- Free Softwares: softwares de livres distribuição e utilização em geral escrito por programadores generosos e abnegados, quase sempre estudantes de computação que querem mostrar do que são capazes. A palavra "free" em inglês pode significar "livre" ou "grátis", o que causa grande confusão e por esse motivo, muitos defensores do software livre estão preferindo usar o termo "open source".

- Freeware: é definido como uma "designação genérica de softwares gratuitos", que inclui tanto os "free softwares" (como Linux) quanto produtos fechados distribuídos gratuitamente em função de estratégias mercadológicas.

- Open-Source: termo adotado por muitos defensores de software livre para evitar confusões como "freewares" e tornar o conceito mais atraente ao corporativo. O programa deve ter seu código fonte publicado na Internet, para que qualquer programador possa estudá-lo e aperfeiçoá-lo. Além disso a licença deve permitir a livre distribuição e utilização do programa, seja para fins comerciais, educacionais ou quaisquer outros.

- Freemium: vem da junção de duas palavras em inglês, "Free" e "Premium". Para Cipoli (2020, p.11), "essa modalidade permite que usuários utilizem um determinado programa sem 
custo algum, mas os recursos mais avançados ficarão disponíveis apenas para quem desejar investir". Portanto, é possível entender que, embora o programa seja gratuito, há uma cobrança por detrás de algumas funções adicionais que um software provém. Em sistemas ERP é possível entender que essas cobranças estejam relacionadas à módulos adicionais, e para o usuário adquirir esses módulos, teria que fazer a compra dos mesmos, ou a obtenção de um pacote para que estes módulos fiquem disponíveis.

\section{PROCEDIMENTOS METODOLÓGICOS}

A metodologia de pesquisa deste artigo envolve pesquisa bibliográfica descritiva de natureza aplicada com abordagem qualitativa, bem como uma análise comparativa entre duas ferramentas: MarketUP e FoxManager. A pesquisa bibliográfica embasa sistemas de informação, sistemas ERP e mercados de softwares, que segundo Chiara (2008) "é feita com o intuito de levantar um conhecimento disponível sobre teorias, a fim de analisar, produzir ou explicar um objeto sendo investigado".

A pesquisa descritiva, segundo Casarin e Casarin (2012, p. 32), “explora uma metodologia predominantemente descritiva, deixando em segundo plano modelos matemáticos e estatísticos. Nesse tipo de pesquisa, a quantificação dos objetos estudados não é prioridade”. Complementar a esse contexto, a abordagem qualitativa, segundo Gerhardt e Silveira (2009, p. 31), "não se preocupa com representatividade numérica, mas, sim, com o aprofundamento da compreensão de um grupo social, de uma organização".

De acordo com Prodanov e Freitas (2013, p. 38), a análise comparativa "realiza comparações com o objetivo de verificar semelhanças e explicar divergências". E que "o método comparativo, ao ocupar-se das explicações de fenômenos, permite analisar o dado concreto, deduzindo elementos constantes, abstratos ou gerais nele presentes".

\section{RESULTADOS E DISCUSSÕES}

No que concerne a pesquisa realizada por este artigo, é constatado que há poucos sistemas ERP gratuitos disponíveis no mercado, pois muitos sistemas que se intitulam gratuitos, na verdade são Freemium, que embora o usuário possa criar e utilizar a plataforma, precisa em 


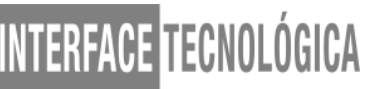

algum momento pagar uma taxa para a obtenção de um novo módulo ou função dentro do próprio ERP. Por mais que o custo por de trás destes softwares Freemium seja relativamente baixo se comparado a aquisição de um programa totalmente proprietário, ou de um programa desenvolvido em uma Software House, para o proprietário de uma empresa de pequeno porte, pode acabar sendo inviável. Nas pesquisas realizadas, foram encontrados dois ERPs: MarketUP e FoxMenager, que são sistemas integrados que podem ser utilizados de forma totalmente gratuita, tanto em empresas de pequeno porte ou de qualquer outra proporção.

O MarketUp é um software criado com parcerias entre empresas fornecedoras, como exemplo, o Sebrae. É um sistema ERP completo, possuindo módulos de gestão, controle de estoque, emissão de notas fiscais, relatórios, entre outros. Além da utilização gratuita do sistema, também é oferecido um treinamento online, através de vídeos expostos na plataforma do YouTube. O usuário ainda pode contar com um suporte técnico através de um chat online ou por atendimento via aplicativo do WhatsApp, sendo esse suporte responsável por solucionar possíveis problemas técnicos ou esclarecer possíveis dúvidas. Vale comentar que, o suporte da MarketUP costuma ser rápido, demorando no máximo 1 dia útil para retornar uma resposta. $\mathrm{O}$ chatbot fica disponível por 24 horas e os demais canais de atendimento ao usuário funcionam de segunda a sábado, das $8 \mathrm{hs}$ até as $22 \mathrm{hrs}$. O sistema pode ser adquirido e acessado através do site da própria MarketUp. A Figura 1 mostra a tela principal do sistema.

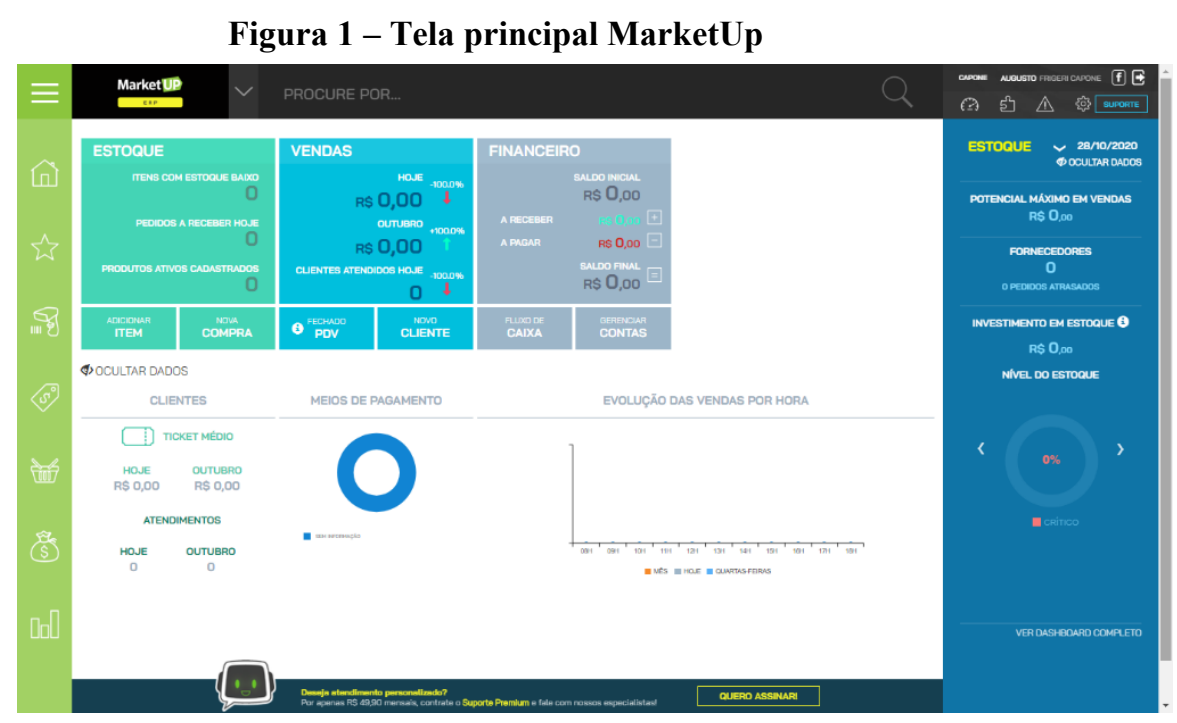

Fonte: MarketUp (2021).

Os fundadores da MarketUP, Carlos Azevedo, Hélio Rotenberg, Alexandre Hohagen e 


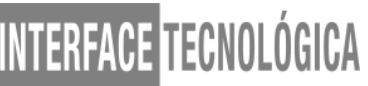

Romero Rodrigues, com sua expertise em empreendedorismo, acreditam que é possível aprimorar o mercado para trazer vantagens e comodidade aos pequenos empreendedores (MARKETUP, 2021). Marketup (2021, p.1) afirma que "a redução da taxa de mortalidade de pequenos negócios fez com que $80 \%$ das empresas fechassem em menos de cinco anos". Ele apresenta uma plataforma online com um serviço em nuvem para o armazenamento de dados e com isso, não necessariamente demanda ao usuário utilizar-se de uma plataforma desktop, pois é possível acessar o sistema através de qualquer aparelho que tenha acesso a um navegador de internet, como tablets ou smartfones. O armazenamento em nuvem traz comodidade ao usuário, já que os dados corporativos estarão salvos e seguros, armazenados nos servidores da Amazon, uma das maiores empresas atuais no ramo de backup em nuvem, além disso os dados são criptografados e apenas os desenvolvedores do software tem acesso às informações valiosas dos usuários.

Neste sistema, pode-se utilizar a câmera do celular como leitor de código de barras, gerenciar e cadastrar vendas, e ainda é possível até mesmo se gerar as notas fiscais. Outra função existente é a de comandas voltadas para bares e restaurantes, em que o atendente pode fazer anotações dos pedidos dos clientes diretamente pelo aplicativo, tornando-o simples e intuitivo. É possível ainda se integrar o ERP com maquininhas de cartão graças a uma parceria com a Cielo, podendo assim ser gerado notas fiscais através da aplicação mobile. Todas as funções podem ser acessadas de maneiras rápidas em um menu sugestivo no lado esquerdo do programa, onde é possível acessar a todos os módulos e funções como mostra a Figura 2.

Figura 2 - Barra de Funções MarketUP

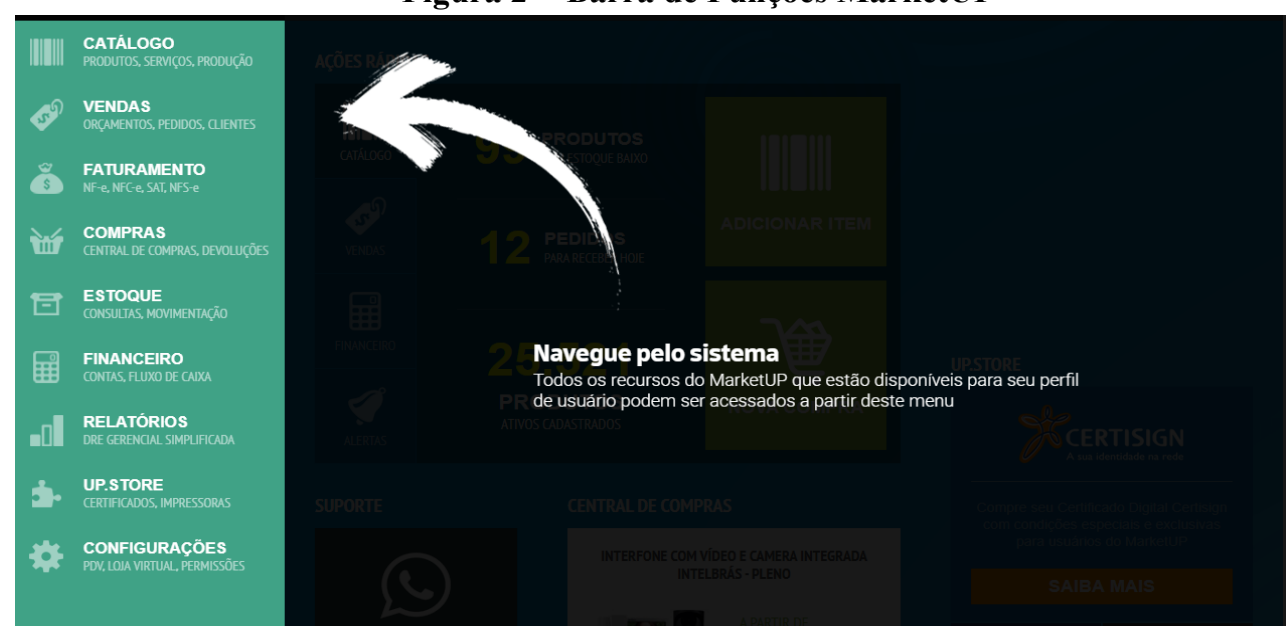

Fonte: MarketUp (2021). 
Ao criar uma conta na MarketUP é possível fazer algumas personalizações de acordo com o tipo de negócio que a empresa segmenta. É notável que o MarketUP consiga atender uma gama de negócios muito grande, em que um único software pode alcançar um número enorme de usuários. No geral, pode-se relatar que as interfaces dos sistemas são diretas e claras, possuindo alta usabilidade. "Atualmente, já são 850 mil empresas cadastradas no MarketUP, e 26 mil novas empresa por mês" (MARKETUP, 2021, p.2).

O FoxManager, igualmente ao MarketUp, oferece muitas funções de seu sistema de forma gratuita, porém há limitações para os usuários que utilizam a versão free. Mensalmente na versão gratuita, o usuário poderá gerar apenas 20 unidades de notas fiscais e boletos (FOXMANAGER, 2021). Em outras versões, estes números são alterados, chegando até mesmo ser ilimitado. Para uma empresa pequena, que não venha a utilizar de muitas notas fiscais e boletos, é possível que este número de notas não venha a interferir em seu negócio de forma negativa. Embora tenha estas limitações, o sistema não se classifica como um Freemium, já que o usuário tem o mesmo acesso de módulos das versões pagas, porém apenas com desvantagens de algumas limitações. É possível acessar o sistema através de um celular, porém não há um aplicativo disponível nas plataformas da AppleStore e da PlayStore, portanto o acesso ocorrerá através de um navegador. A Figura 3 mostra a tela principal do FoxMenager.

Figura 3 - Tela principal do FoxMenager

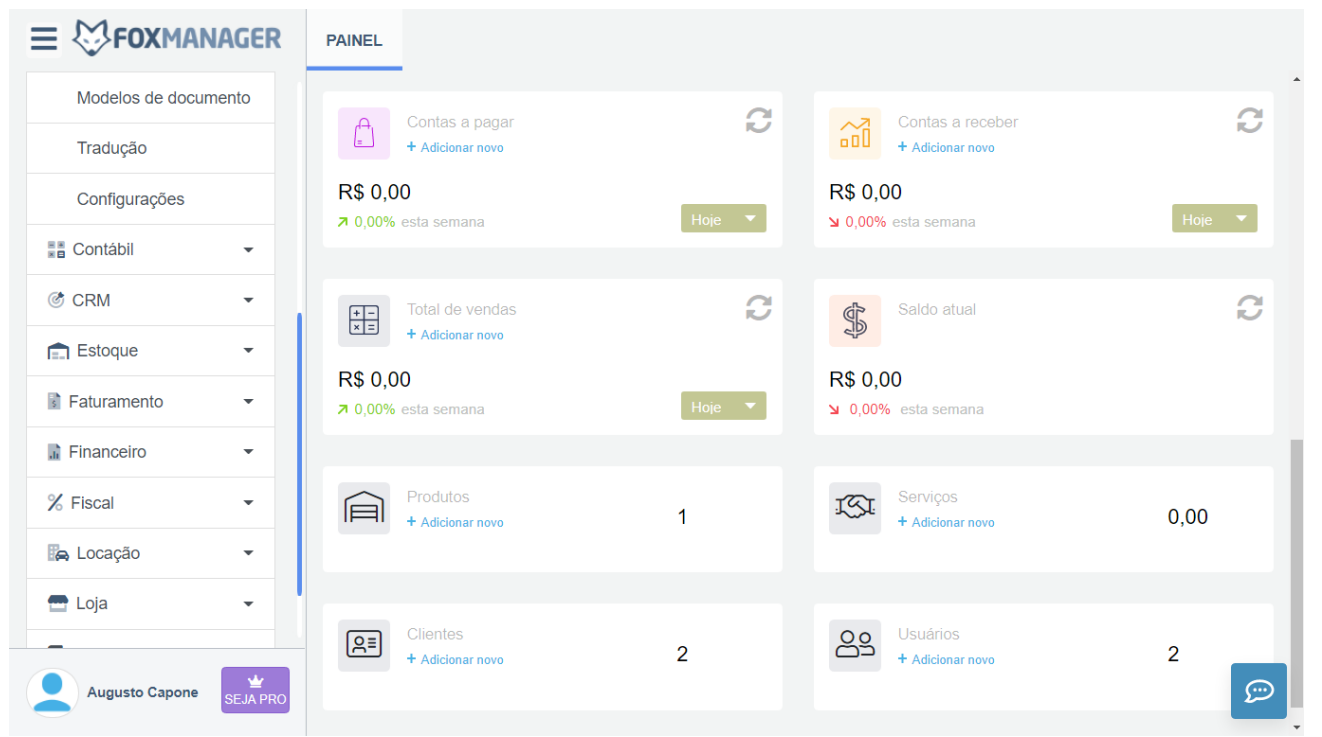

Fonte: FoxManager (2021). 


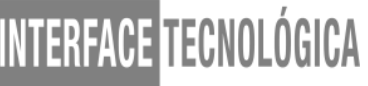

Pelo fato da tela do celular ser pequena, ao entrar na página do software, algumas informações são cortadas e é necessário utilizar uma barra de rolagem na horizontal, perdendo usabilidade. Algo que venha a ser um aspecto negativo é o acesso ao suporte, pois há versões em que o usuário pode entrar em contato direto com um suporte especializado através de um chat online, ou até mesmo enviar ilimitadamente vários números de chamados de emergência, contudo, na versão gratuita, este tipo de serviço não é prestado, precisando enviar um e-mail ou entrar em contato através do site.

Não foi encontrado conteúdo de treinamento, porém, existem vídeos disponíveis em plataformas como o YouTube, não existindo vídeos vinculados à empresa e sim feitos por usuários como forma de ajudar outros membros da comunidade. O software consegue atender uma vasta gama de tipos de mercados, desde comércios varejistas e atacadistas, escritórios de contabilidade, pet shops, mercados, lojas de peças e entre outros. E todos os módulos são disponíveis de forma fácil e prática na parte esquerda. Outra praticidade envolve as abas abertas exibidas na parte superior da tela, que se assemelham as usadas em um navegador Web, que servem para o usuário fechar ou voltar para uma aba anterior. Esta função ajuda em uma melhor navegação. Além destes aspectos, na tela inicial, o usuário pode encontrar alguns dashboards para facilitar em sua navegação. Fundado por Antônio Morais, o software oferece pacotes como mostra a Figura 4. 
Figura 4 - Pacotes do FoxManager

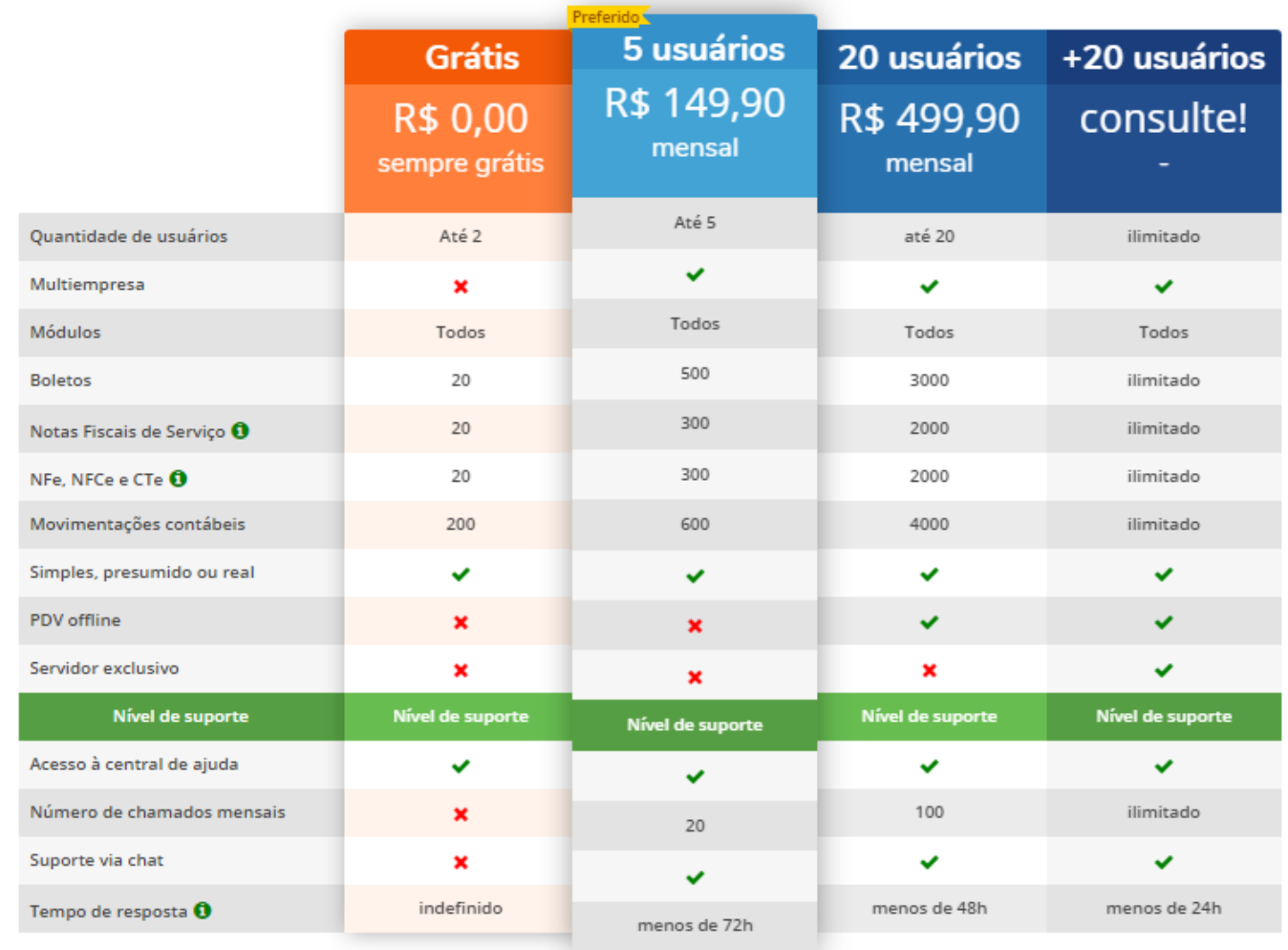

Fonte: FoxManager (2021).

Pode-se observar algumas diferenças entre os pacotes pagos e os gratuitos, como o número de usuários que podem ter acesso, quantia de boletos e notas fiscais que podem ser gerados por mês, plataforma offline, número de chamadas mensais, suporte via chat entre outros.

\section{CONSIDERAÇÕES FINAIS}

O objetivo deste artigo envolveu apresentar dois sistemas ERP gratuitos, mostrando algumas vantagens e recursos. Uma análise comparativa foi realizada utilizando-se dos seguintes critérios: aplicação mobile, gratuidade, módulos gratuitos, suporte e treinamento ao usuário, notas fiscais, mercado atuante, interface abrangência funcional, relatórios e customização. Nem todas as informações analisadas foram apresentadas, porém, pode-se ver muitos desses critérios, os quais podem auxiliar empresas na escolha, implantação e uso dos ERPs apresentados. Alguns ERPs podem ser caros e embora não existam muitos sistemas gratuitos, os poucos disponíveis podem atender as necessidades que uma empresa venha a ter. 


\section{REFERÊNCIAS}

ALBERTÃO, S. E. ERP sistema de gestão empresarial: metodologia para avaliação, seleção e implantação para pequenas e médias empresas. 2.ed. São Paulo: IGLU, 2005.

AQUINO, J.A. Software Livre e Desenvolvimento de Trabalhos Científicos: o R como exemplo a ser seguido. Revista Política Hoje, v. 24, ed.2, 2015.

CASARIN, H. C. S; CASARIN, S. J. Pesquisa científica: da teoria à prática. Curitiba: InterSaberes, 2012.

CIPOLI, P. O que é Freemium? CanalTech. 2020. Disponível em: https://canaltech.com.br/software/O-que-e-Freemium/. Acesso em: 10 abr. 2021.

CHIARA, I. D, KAIMEN, M. J, CARELLI, A. E, CRUZ, V. Normas de documentação aplicadas à área de Saúde. Rio de Janeiro: E-papers, 2008.

FERREIRA, A. C; SILVA, G. Sistema de Gestão Empresarial Baseado no Conceito de Enterprise Resource Planning (ERP). 2004. 80 p. Monografia (Graduação em Análise de Sistemas) - Universidade Católica de Pelotas, Rio Grande do Sul, 2004.

FOXMANAGER. Módulos Principais: Módulos do FoxMenager. Disponivel em: https://foxmanager.com/br/. Acesso em: 13 abr. 2021.

GARCIA. M. Informática Aplicada a negócios. 1.ed. Rio de Janeiro: Brasport, 2005. GERHARDT, T. E; SILVEIRA, D.T. Métodos de pesquisa. Porto Alegre: Editora da UFRGS, 2009.

HEXSEL, R. A. Software livre: Propostas de Ações de Governo para Incentivar o Uso do Software Livre. Curitiba; 2002 (Relatório Técnico n. RT-DINF 004/2002).

MARKETUP. Sobre o Sistema de Gestão Grátis. Disponível em: https://marketup.com/. Acesso em: 13 abr. 2021.

MATTOS, A. C. M. Sistemas de informação: uma visão executiva. 2. ed. São Paulo: Saraiva, 2005.

MENDES, J. V; ESCRIVÃO FILHO, E. Sistemas Integrados de Gestão (ERP) em Pequenas e Médias Empresas: Um Confronto entre a Teoria e a Prática Empresarial. São Paulo: Atlas, 2003.

OLIVEIRA, D. P. R. Sistemas de informação gerenciais: estratégias, táticas, operacionais. 8. ed; São Paulo: Atlas, 1992.

PRODANOV, C. C; FREITAS, E. C. Metodologia do Trabalho Científico: Métodos e Técnicas da Pesquisa e do Trabalho Acadêmico. 2. ed. Rio Grande do Sul: Universidade Feevale, 2013.

REZENDE, D. A. ABREU, A. F. Tecnologia da informação: aplicada a sistemas de informação empresariais. 9. ed; São Paulo: Atlas, 2013.

SEBRAE. Sobrevivência das Empresas no Brasil: Coleção Estudos e Pesquisas. Brasília, 2013, p. 19-22. Disponível em: 
https://www.sebrae.com.br/Sebrae/Portal\%20Sebrae/Anexos/Sobrevivencia_das_empresas_n o_Brasil=2013.pdf. Acesso em: 13 abr. 2021.

ZWICKER, R; SOUZA, C. A. Sistemas ERP: Conceituação, ciclo de vida e estudos de casos comparados. In: SOUZA, Cesar Alexandre; SACCOL, Amarolinda Zanela (Org.). Sistemas ERP no Brasil (Enterprise Resourse Planning): Teoria e casos. São Paulo: Atlas, 2011. 